Case Report

\title{
TYPE III CAWLEY ANDERSSON LESION IN A CASE OF ANKYLOSING SPONDYLITIS
}

\author{
Deepak Hegde ${ }^{1}$, Arjun Ballal ${ }^{2}$, Vinay Kumar $C^{3}{ }^{3} \&$ H. Ravindranath Rai ${ }^{4}$ \\ ${ }^{1}$ Associate Professor, ${ }^{2,3}$ P.G. Students, ${ }^{4}$ Professor \& HOD, Department of Orthopaedic Surgery, \\ K. S. Hegde Medical Academy, Nitte University, Deralakatte, M angalore-575018, Karnataka, India. \\ Correspondence \\ Arjun Ballal \\ P.G. Student, Department of Orthopaedic Surgery, K.S.Hegde M edical Academy, Nitte University \\ Deralakatte, Mangalore - 575 018, Karnataka, India. \\ Mobile : +918431644077 E-mail : arjchess_Ip@ rediffmail.com
}

\begin{abstract}
:
Ankylosing spondylitis (AS) is a chronic inflammatory disease that affects especially males in the second and third decades of life. ${ }^{1}$

The main clinical symptom is inflammatory back pain typically occurring at night and morning stiffness improving after exercise. ${ }^{1}$

Apart from syndesmophytes and ankylosis of the spine resulting in rigidity, in longstanding ankylosing spondylitis, also focal destructive discovertebral lesions (Andersson lesions) can occur. ${ }^{1}$

The case we present here is of a 35 year old male patient who presented to us with the symptoms of pain of upper back and both shoulders for 6 years. Pain was followed with stiffness of the neck and shoulder. Radiography of the dorsolumbar spine revealed squaring of the vertebra, syndesmophytes, calcification of the anterior spinal ligament, end plate irregularity at D10-D11 level, ill defined sclerosis with fracture of the ankylosed spine, features consistent with Andersson lesion type III. He underwent posterior spinal fusion with good functional outcome.
\end{abstract}

Keywords: Andersson Lesion, Ankylosing Spondylitis, Cawley classification, Spinal fusion, Dorsolumbar spine

\section{Introduction:}

Ankylosing spondylitis (AS) is a chronic inflammatory disease that affects especially males in the second and third decades of life. ${ }^{1}$

The main clinical symptom is inflammatory back pain typically occurring at night and morning stiffness improving after exercise. The pain, stiffness, and limited mobility of the spine can cause severe limitations in daily life activities. Inflammation in AS usually is localized in the sacroiliac joints and the axial skeleton. ${ }^{1}$

Apart from syndesmophytes and ankylosis of the spine resulting in rigidity, in longstanding ankylosing spondylitis,

\begin{tabular}{|c|}
\hline Access this article online \\
\hline Quick Response Code \\
\hline
\end{tabular}

also focal destructive discovertebral lesions, Andersson lesion can occur. ${ }^{1}$

In 1996, Rasker et al. described six cases of spondylodiscitis in ankylosing spondylitis. ${ }^{2}$
Andersson lesions radiologically show ${ }^{1}$ :

a) Diskspace narrowing or widening.

b) Vertebral bone destruction, a surrounding zone of sclerosis.

c) Local kyphosis at radiographs of the spine.

One of the causes of an Andersson lesion is the local inflammation in the spine in combination with a minor trauma. This lesion can be differentiated from the signs of inflammation at the MRI of the spine of active disease in ankylosing spodylitis. ${ }^{1}$

Cawley and colleagues classified them into 3 types ${ }^{3}$.

Type I: Lesions involve the central portion of the discovertebral junction that is covered by cartilage.

Type II: Lesions involve the peripheral portion of discovertebral junction not covered by cartilaginous endplate.

Type III: Lesions involve both the peripheral and central portions. 


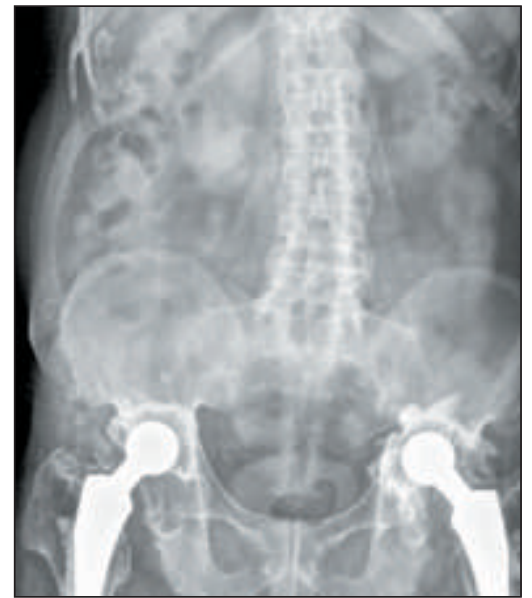

Fig 1

Fig. 1: X-ray of Lumbosacral spine showing squaring of vertebra with syndesmophytes. Note the bilateral total hip arthroplasty the patient underwent 4 years back.

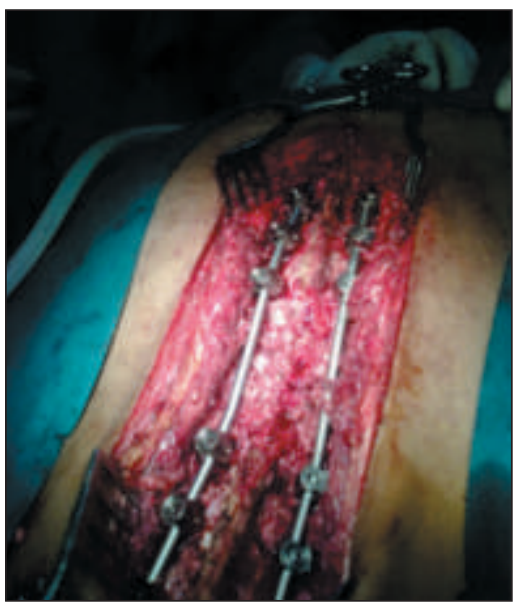

Fig 4

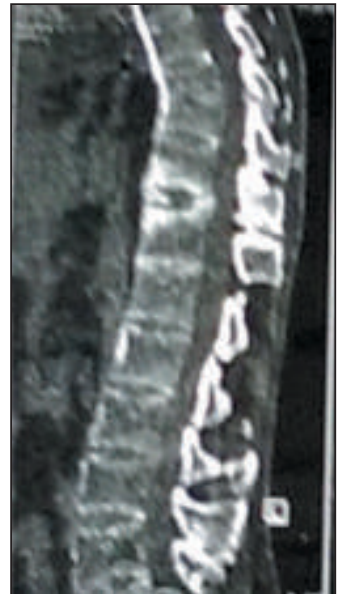

Fig 2

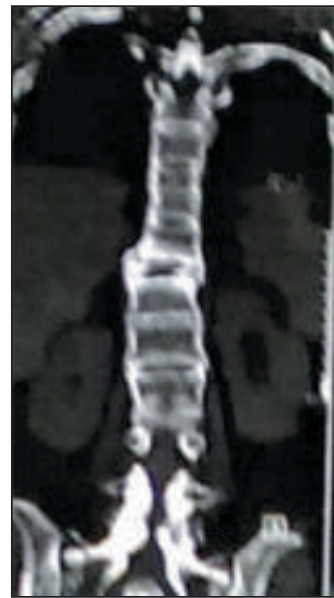

Fig 3

Fig. 2, 3: M RI of dorsolumbar spine showing calcification of anterior spinal ligament and ill-defined sclerosis with ankylosed spine consistent with Type III Cawley Andesson lesion.

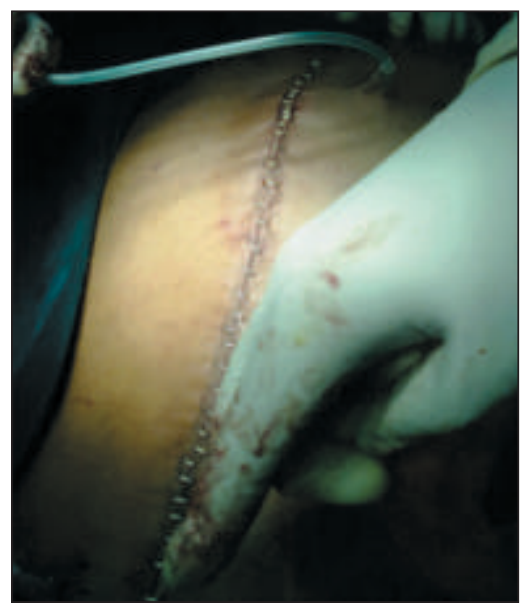

Fig 5

Fig 4 \& 5 : Intra-operative photographs showing posterior instrumentation with monoaxial $5 \mathrm{~mm}$ pedicle screws from D6-L3 and after skin closure respectively.

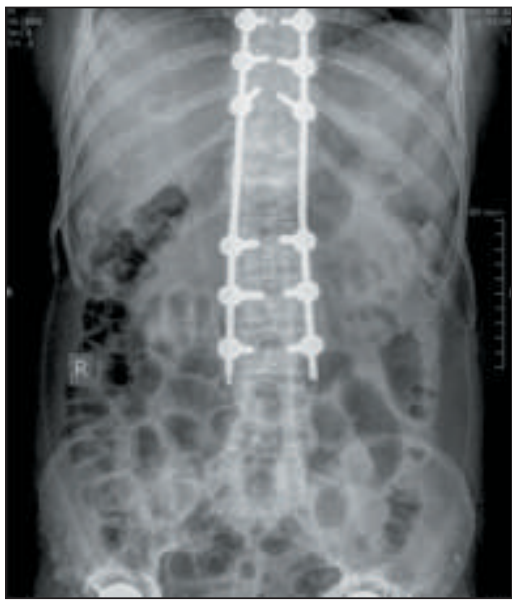

Fig 6

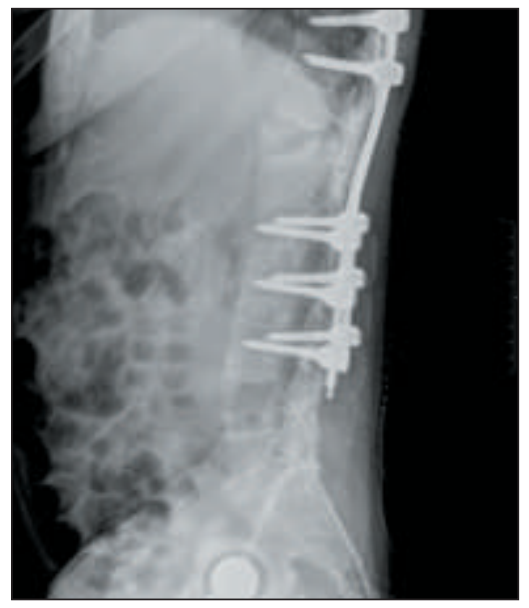

Fig 7

Fig. 6 \& 7: Post-operative x-rays Antero-posterior/ Lateral views showing post D6-L3 stabilization 


\section{Case Report:}

A 35 year gentleman presented to us with symptoms of pain over upper back and both shoulders for 6 years. Pain was insidious in onset $\&$ progressive. Subsequently, he developed stiffness of the neck and shoulder which was progressive in nature, due to which he developed difficulty in turning the neck and back.

There was no history of trauma or fall. There was no history suggestive of development of any neurological deficits.

He gave us the history of undergoing bilateral total hip replacement 4 years back.

On examination, the cervical spine was fixed in about 30 degrees of flexion with lateral rotation to the right side, flexion at the thoracolumbar spine was noted to be from 0 to 40 degrees and was painful. Chest expansion was reduced. Schober'stest was positive.

Radiologically the dorsolumbar spine showed: (Figures $1,2,3)$

a) Squaring of the vertebra

b) Syndesmophytes

c) Calcification of the anterior spinal ligament, end plate irregularity at D10-D11 level.

d) Cobb'sangle was 40 degrees.

e) III defined sclerosis with fracture of the ankylosed spine consistent with Andersson lesion type III.

He underwent posterior decompression surgery and posterior spinal fusion with bone grafting. Pedicle screw fixation was done from D6-L3vertebra bilaterally using monoaxial $5 \mathrm{~mm}$ pedicle screw. (Figures 4,5 )

Postoperative X-ray was satisfactory with correction of kyphosis from 40 to 20 degree. Biopsy shows inflammatory cells and features suggestive of ankylosing spondylitis. (Figures 6, 7)

On postoperative day 6 , discharge was noted at the surgical site for which he underwent debridement and pus was sent for culture and sensitivity.
Culture revealed Staphylococcus aureus for which appropriate antibiotics were started as per the sensitivity.

At the third month of follow up, X-rays were taken which showed bony consolidation at D11-D12 with loosening of distal screw on the left side which was managed conservatively.

\section{Discussion:}

Discovertebral lesions are frequently termed Andersson lesions, who described them in two patients with ankylosing spondylitis in $1937{ }^{4}$

Wang $G$ et al conducted a prospective study on eight patients with Andersson lesion who underwent surgical stabilization and concluded that surgical treatment with only posterior instrumentation supplemented by posterolateral autograft was effective for patients with Andersson lesions without obvious vertebral body destruction requiring reconstruction. ${ }^{5}$

Park YS et al concluded that the inflammatory Andersson lesion were associated with recent onset disease and responded well to medical treatment whereas the traumatic variety were of prolonged duration and responded to surgical intervention. ${ }^{6}$

Dhakad U and Das SK reported a patient who presented with features of TB spine and was managed accordingly. Reevaluation concluded Andersson lesion and conservative management with cytolytic agents and steroids improved his symptoms. ${ }^{.}$

Cawley et al, classified them into three types:

Type I: Lesions here are localised to the central subchondral portions of the discovertebral junction and this can occur in both ankylosed and non-ankylosed spines. Osteoporosis of vertebrae are marked in ankylosing spondylitis. This results in weakening of the subchondral bone and displacement of the discal contents through the cartilaginous end plate into the vertebral body.

Apophyseal joint involvement may lead to instability and recurrent traumatic insult to the disc-bone interface. 
This eventually produces infarction of cartilaginous endplate allowing the discal material into the vertebral body. Inflammatory changes in subchondral bone itself may lead to osseous weakening and discal displacement. Radiologically, the lesions appear as irregularity of central portion of the superior and inferior vertebral margins with surroundingsclerosis.

Type II: These are peripheral localized lesions occurring in the anterior or posterior part of discovertebral junction. The anterior lesion is attributed to collapse of osteoporotic anterior vertebral margin as occurs in osteoporotic kyphosis and also alternatively to injury to the anterior fibres of annulus fibrosus. These lead to invasion and replacement of discal material by vascular fibrous tissue as in senile kyphosis. The mechanism of the localised posterior lesions though not clear may be due to osteoporotic collapse or cartilagenous nodes. Radiologically, Type Il lesions are seen as intervertebral disc space narrowing with bony sclerosis, irregularity of discovertebral junction and anterior or posterior discovertebral erosion with intact apophyseal joints.

Type III: Destruction of the whole discovertebral junction

\section{References:}

1. De Vries M K, van Drumpt AS, van Royen BJ, van Denderen JC, Manoliu RA, van der Horst-Bruinsma IE. Discovertebral (Andersson) lesions in severe ankylosing spondylitis: a study using MRI and conventional radiography. Clin Rheumatol (2010) 29:1433-1438.

2. Rasker JJ, Prevo RL, Lanting PJ Spondylodiscitis in ankylosing spondylitis, inflammation or trauma? A description of six cases. Scand J Rheumatol 1996 25(1):52-57

3. Cawley, Chalmers, Kellgren. Destructive lesions of vertebral bodies in ankylosing spondylitis. Ann Rheum Dis1972; 31: 345.

4. Bron JL, de Vries MK, Snieders M N, van der Horst-Bruinsma IE, van Royen BJ, Discovertebral (Andersson) lesions of the spine in ankylosing spondylitis revisited. Clin Rheumatol. 2009 Aug;28(8):88392

5. Wang G, Sun J, Jiang Z, Cui X. The surgical treatment of Andersson lesions associated with ankylosing spondylitis. Orthopedics. $2011 \mathrm{Jul}$ 7;34(7):e302-6

6. Park YS, Kim JH, Ryu JA, Kim TH. The Andersson lesion in ankylosing spondylitis: distinguishing between the inflammatory and traumatic subtypes. J Bone Joint Surg Br. 2011 Jul;93(7):961-6.

7. Dhakad U and Das SK Andersson lesion in ankylosing spondylitis BMJ Case Rep. 2013, Apr 3;2013. of two adjacent vertebral bodies occurs in patients with advanced ankylosis. There may be a history of trauma and associated fracture through the ankylosed portion. There may be improper healing with callus formation, haemorrhage and minimal inflammatory changes. The radiological appearance of this type is a combination of Type land Type ll lesions.

The radiological features of all types of Andersson lesion including disc space narrowing, destruction of vertebral end plate and sclerosis of adjacent bone mimic infective spondylitis particularly due to tuberculosis. ${ }^{7}$

Our patient had a disease duration of 6 years with postural deformity. He had no history of trauma. Infection was ruled out in this case. He underwent decompression surgery and posterior spinal fusion.

The significance of Andersson lesion is that it occurs frequently in anklylosing spondylitis of longer disease duration and mimics infection. ${ }^{6}$

Knowledge of these lesions and thorough screening help us to avoid subjecting these patients to treatment strategies forinfection. 